\title{
Characteristics of Oxidative Storage Stability of Canola Fatty Acid Methyl Ester Stabilised with Antioxidants
}

\author{
Tirto Prakoso ${ }^{1}$, Parncheewa Udomsap ${ }^{2}$, Akiko Tanaka ${ }^{3}$, Toshihiro Hirotsu ${ }^{3}$ \\ \& Shinichi Goto ${ }^{3}$ \\ ${ }^{1}$ Department of Chemical Engineering, Bandung Institute of Technology (ITB), \\ Jl. Ganesha 10, Bandung, Jawa Barat 40132, Indonesia \\ ${ }^{2}$ National Metal and Materials Technology Center (MTEC), NSTDA114 Paholyothin \\ Rd.,Klong 1, Klong Luang, Pathumthani 12120, Thailand \\ ${ }^{3} \mathrm{NFV}$ Center, National Institute for Advanced Industrial Science and Technology \\ (AIST), 1-2-1 Namiki, Tsukuba, Ibaraki 305-8564, Japan \\ Email: tirto@che.itb.ac.id
}

\begin{abstract}
The storage effects on the oxidation characteristics of fatty acid methyl ester of canola oil (CME) were investigated in this study.CME stabilised with two antioxidants, i.e.2,6-di-tert-bytyl-p-cresol (BHT) and 6,6-di-tert-butyl$2,2^{\prime}$-methylendi-p-cresol (BPH), was stored at 20,40 and $60^{\circ} \mathrm{C}$. The oxidation stability data were measured by the Rancimat test method and it was found that both BHT and BPH addition increased the oxidation resistance of the CME. The results showed that when $\mathrm{BPH}$ or BHT was added at a concentration of $100 \mathrm{ppm}$, the oxidation induction period of the neat CME samples increased from $5.53 \mathrm{~h}$ to 6.93 hand $6.14 \mathrm{~h}$, respectively. Comparing both antioxidants, BPH proved to be more effective in increasing the oxidation resistance when both antioxidants were added at the same concentration. Furthermore, the oxidation induction time decreased linearly with the storage time. It was shown that the oxidation occurred rapidly in the first 8 weeks of storage. Later, a kinetic study was undertaken and first-order kinetics were applied to explain the oxidation characteristics of the CME added with antioxidants. This kinetic study focused on exploiting the activation energy values obtained from the Arrhenius equations. Also, the oxidation effects on other quality parameters, including acid value, peroxide value, kinematic viscosity, and water content, were examined.
\end{abstract}

Keywords: antioxidants concentration; canola fatty acid methyl ester; oxidation stability; temperature effects; time of storage.

\section{$1 \quad$ Introduction}

Recently, biodiesel of methyl ester, one of several alternative diesel fuels, is made from vegetable oil and animal fat through methanol transesterification. Interest has been aroused in their use as they are biodegradable and release a low level of toxic gas emissions into the environment. The mechanism of transesterification reaction consists of three reversible reactions, in which triglyceride is converted into diglyceride, monoglycerides and glycerol

Received April $7^{\text {th }}, 2011$, Revised June $19^{\text {th }}, 2012$, Accepted for publication November $1^{\text {st }}, 2012$

Copyright (C) 2012 Published by LPPM ITB \& PII, ISSN: 1978-3051, DOI: 10.5614/itbj.eng.sci.2012.44.3.7 
sequentially [1]. The composition of the fatty acid structure is determined by the type of feedstock [2], while the optimum reaction conditions depend on the state of the supplied oil, which has been investigated for the effective production of biodiesel fuel. Each type of biodiesel feedstock contains its own fatty acid composition, and this chemical structure influences the properties of methyl ester as a biodiesel fuel, such as oxidation stability, cetane number, iodine value, cold filter plugging point, etc. [2]. The presence of free fatty acids and water always brings negative effects to the biodiesel yield owing to soap formation and the consumption of alkaline catalysts. As a result, the addition of an alkaline catalyst decreases reaction effectiveness and a gives lower yield [3, 4]. The conditions for biodiesel production are considered optimal when they have a high yield of alkyl ester, are easy to operate and cost-effective.

The combustion properties of biodiesel fuel are similar to those of petroleum diesel fuel. One important quality of good biodiesel fuel is its resistance to oxidation during storage, especially under high-temperature conditions and on air exposure. The relative rates of oxidation of polyunsaturated fatty acids, like linolenate and linoleate methyl esters, are higher than those of monounsaturated fatty acids, like oleate methyl esters [5].The presence of double bonds in fatty acid molecules can result in a high level of reactivity with oxygen when the fuel is exposed to air during storage. Besides the presence of air, other factors that affect the oxidation process of biodiesel include presence of light, heat, traces of metal, peroxide and the surface area between biodiesel and air [6]. Thus storage and handling are also important factors that can affect the oxidation of biodiesel. The oxidation finally results in the formation of carboxylic acids with high molecular weight as well as low molecular weight [7]. These substances will cause an increase in the viscosity of the biodiesel fuel, which can result in fuel line and pump clogging. The peroxides produced during oxidation will also cause an increase in cetane number, which can have a negative effect on the plastic and elastomer partsof an engine, such as swelling and ageing problems. Moreover, the acid forms will cause corrosion on metal components [8].

One approach to increase the oxidation resistance of biodiesel is to treat it with an oxidation inhibitor or antioxidant. Commonly used antioxidants are monohydroxy or polyhydroxy phenol compounds with various ring substitutions. These antioxidant compounds have low activation energy to donate hydrogen in order to interrupt the propagation of the free radical chain. In other words, the compounds can delay the start and/or slow down the chemical reaction rate of oxidation. The resulting antioxidant free radicals do not initiate other free radicals due to the stabilisation by delocalisation of the radical electron and it can also react with lipid free radicals to form stable complex compounds [9]. 
The purpose of this work is to investigate the oxidation characteristics of canola fatty acid methyl ester (CME). Canola is one of two cultivars of rapeseed that produce edible oil. CME was produced on a laboratory scale to be used for the investigation. The reason Canola has been chosen is that it is very popular and easy to obtain as cooking oil in Japan and European countries. As this type of biofuel consists of a high concentration of unsaturated fatty acid, the oxidation stability is predicted to be considerably lower compared to palm oil, so that it is important to enhance its stability by adding antioxidants. Canola oil's main composition is $60 \%$ oleic acid, $20 \%$ linoleic acid, and $8 \%$ linolenic acid. The remaining percentage consists of stearic and palmitic acids.

Two phenolic types of antioxidants were used in this work, i.e.2,6-di-tert-butyl4-methylphenol (BHT) and 2,2'-methylenebis(6-t-butyl-4-methylphenol) (BPH). Different oxidation states were achieved and as a result the oxidation stability could be controlled. The oxidation stability of the CME stabilised with two types of antioxidants at varying concentrations was examined primarily. Then changes in the oxidation stability index (OSI), expressed by the induction period of the Rancimat test (IP), were monitored during storage. Karavalakis, et al. have investigated the performance of other phenolic antioxidants, such as BHA, on biodiesel blends made from 50\% rapeseed oil, $20 \%$ sunflower oil and $30 \%$ used frying oils [10]. They compared the performance of two phenolic antioxidants, which both only had one phenolic group attached to each molecule. However, BHT has one phenolic group phenolic groups attached to each molecule, while BPH has two. Comparing the two antioxidants, BPH is expected to have an antioxidant performance superior to that of BHT or BHA.

First-order kinetics were then employed to describe the oxidation process according to the observation of a linear relationship between the logarithmic values of the OSI and particular ranges of storage time in this investigation.

The handling provided an explanation for changes in the induction period of the oxidation process. Jiayu Xin, et al. have investigated kinetically the oxidation stability of safflower methyl ester stabilised with propyl gallate at various concentrations and at elevated temperatures [11]. They analysed the oxidation stability data by following the effect of the decrease in antioxidant concentration on the induction period of the Rancimat test to elucidate the oxidation characteristics. Their analysis also employed first-order reaction rate kinetics to illustrate the oxidation of biodiesel fuel. Even though the handling process in our study was different from their case, in which this was based on the chemical reactions because of the decreasing density of the antioxidants, first-order kinetics could also be applied to the storage tests. 
By comparing the assumed rate constant obtained from storage temperatures of 20,40 and $60^{\circ} \mathrm{C}$, the activation energy was calculated from the Arrhenius plots of each CME sample. Thus the oxidation characteristics could be compared to each other. These could be further related to other quality parameters, such as the acid value and peroxide value, which also varied over the storage period of the biodiesel fuel.

\section{Experiment}

\subsection{Chemical and Materials}

Methanol, potassium hydroxide $(\mathrm{KOH})$, sulfuric acid and glycerol of reagent grade were purchased from Wako Pure Chemicals Industries, Ltd., Tokyo, Japan. Antioxidants BHT and BPH were reagent grade and purchased from Wako also. Canola oil (Nisshin Oilio, Ltd., Japan), which had been purchased in the market, was used as the source for the CME.

\subsection{Preparation of CME}

Transesterification of food grade canola oil was carried out. Firstly, $\mathrm{KOH}$ $(1.67 \% \mathrm{w} / \mathrm{w}$ of oil) was dissolved in methanol $(22.50 \% \mathrm{w} / \mathrm{w}$ of oil) and the mixture was added to vegetable oil. The excess $\mathrm{KOH}$ and excess methanol $(14 \% \mathrm{w} / \mathrm{w}$ oil $)$ were added to the mixture in order to meet the minimum ester content of $96.5 \%$ at the end of the reaction. The mixture was then preheated to $60^{\circ} \mathrm{C}$ under stirring for 1 hour. The separated fatty acid methyl ester layer was washed with water to remove residual acid and methanol, and subsequently the product was dried to remove moisture. The mono-, di- and triglyceride contents of the CME were then analyzed using high-performance liquid chromatography in order to evaluate thecompletion of the reaction.

\subsection{Storage of CME and Oxidation Stability Test}

The neat CMEs and those added with BHT and BPH at a concentration of up to $600 \mathrm{ppm}$ were put in $300 \mathrm{~mL}$ bottles and stored at 20,40 and $60^{\circ} \mathrm{C}$. The oxidation stability tests were carried out every 2 weeks. The peroxide values and acid values were measured every 4 weeks, while kinematic viscosity and water content were measured every 8 weeks. The oxidation stability was evaluated mainly by the induction period tested by a Rancimat apparatus (Type 743, Metrohm Schweiz AG, Switzerland) according to the standard test method specified in BS EN 14112.

\subsection{Chemical Analysis}

The peroxide value was determined by a potentiometric meter (Titrando 809, Metrohm) and the acid value was determined using a potentiometric automatic titrator (GT-100, Mitsubishi Chemical Analitica Co., Japan) in conjunction with 
an auto sample changer (GT-07). The kinematic viscosity of the FAMEs was measured at $40^{\circ} \mathrm{Cby}$ a viscosity meter in a water bath (VB-X6, Yoshida Kagaku Kikai Co., Japan), while the water content was measured using an 831 KarlFischer coulometer (Metrohm). The standards referred to in this research are listed in Table 1.

Table 1 Fatty acid methyl esters analytical standards used in this research.

\begin{tabular}{ll}
\hline Properties & Standard of Analysis \\
Oxidation stability (hours) & EN 14112:2003 \\
Acid value (mg KOH/g) & ASTM D 664-07 \\
Peroxide value (meq/kg) & ISO 27107:2008 \\
Water content (mg/kg) & ISO 12937 \\
Kinematic viscosity (mm/s) & ISO 4104:1996 \\
\hline
\end{tabular}

\section{$3 \quad$ Results and Discussion}

\subsection{Chemical Characterisation of CME}

The chemical properties of the CME are summarised in Table 2 . The acid value and kinematic viscosity of the CME were within the range of the standard levels specified in the EN and ASTM standards. The oxidation stability of the CME was $5.53 \mathrm{~h}$, which corresponds to that of methyl ester prepared from wasted cooking oil. However, the EN standard requires the oxidation stability to reach a minimum of $6 \mathrm{~h}$, therefore a modification of the CME is essential.

The period of oxidation stability required to meet the EN and ASTM standards is $6 \mathrm{~h}$ and $3 \mathrm{~h}$, respectively. However, the standard of the ERIA (Economic Research Institute for ASEAN and East Asia) group, which considers the use of biodiesel fuel mainly in Southeast Asian countries, requires a stability time of longer than $10 \mathrm{~h} \mathrm{[12].} \mathrm{In} \mathrm{order} \mathrm{to} \mathrm{meet} \mathrm{this} \mathrm{ERIA} \mathrm{requirement,} \mathrm{further}$ stabilisation of the CME was necessary. For this purpose antioxidants BHT and $\mathrm{BPH}$ were added. The influence of several parameters, i.e. antioxidant addition, storage temperature and storage period, on the characteristics of the oxidation resistance were then examined.Using these experimental results, the kinetic analyses were attempted and the characterisation of the modified CME was made.

Figure 1shows the effects of the addition of antioxidants BHT and BPH on the induction period of canola methyl ester (CME). Both antioxidants were added at a concentration of up to $600 \mathrm{ppm}$, and the changes in the induction period of the Rancimat test were compared. The influence of these anti oxidants on the increase of the induction period were proved. Furthermore it should be noted that the stability effect was, in general, greater for $\mathrm{BPH}$, in which two atoms of hydrogen in the phenolic hydroxyl form can contribute to the stabilisation. The 
induction period of CME exceeded 6h, which is the EN 14214 standard value when either BHT or BPH are added at $100 \mathrm{ppm}$. In addition, the induction period increased with the increase of the added antioxidant concentrations.

Table 2 Chemical properties of fatty acid methyl esters.

\begin{tabular}{|c|c|c|c|c|c|c|c|}
\hline \multirow[b]{2}{*}{ Properties } & \multicolumn{3}{|c|}{ Standard } & \multirow[b]{2}{*}{ CME } & \multirow[b]{2}{*}{ WCOME } & \multirow[b]{2}{*}{ COME } & \multirow[b]{2}{*}{ JME } \\
\hline & $\begin{array}{c}\text { JISK23 } \\
90\end{array}$ & EN14214 & $\begin{array}{c}\text { ASTM } \\
\text { D6751-08 }\end{array}$ & & & & \\
\hline $\begin{array}{l}\text { 1. Oxidation stability } \\
\text { (h), min }\end{array}$ & - & 6 & 3 & 5.53 & 5.22 & 23.97 & 9.11 \\
\hline $\begin{array}{l}\text { 2. Acid value } \\
(\mathrm{mgKOH} / \mathrm{g}), \max \end{array}$ & 0.5 & 0.50 & 0.50 & 0.15 & 0.15 & 0.08 & 0.16 \\
\hline $\begin{array}{l}\text { 3. Water content } \\
(\mathrm{ppm}), \max \end{array}$ & 500 & 500 & $0.05 \% \mathrm{v} / \mathrm{v}$ & 423.1 & 213.7 & 489.6 & $\begin{array}{c}378 . \\
8\end{array}$ \\
\hline $\begin{array}{l}\text { 4. Kinematic } \\
\text { viscosity } \\
\left(\mathrm{mm}^{2} / \mathrm{s}\right)\end{array}$ & $3.5-5.0$ & $3.5-5.0$ & $1.90-5.00$ & 4.3 & 4.4 & 2.6 & 4.33 \\
\hline $\begin{array}{l}\text { 5. Peroxide value } \\
(\mathrm{meq} / \mathrm{kg})\end{array}$ & $N A$ & $N A$ & $N A$ & 11 & 5.9 & 0.7 & 5.6 \\
\hline
\end{tabular}

CME: canola methyl ester, WCOME: waste cooking oil methyl ester, COME: coconut oil methyl ester, and JME: jatropha methyl ester.

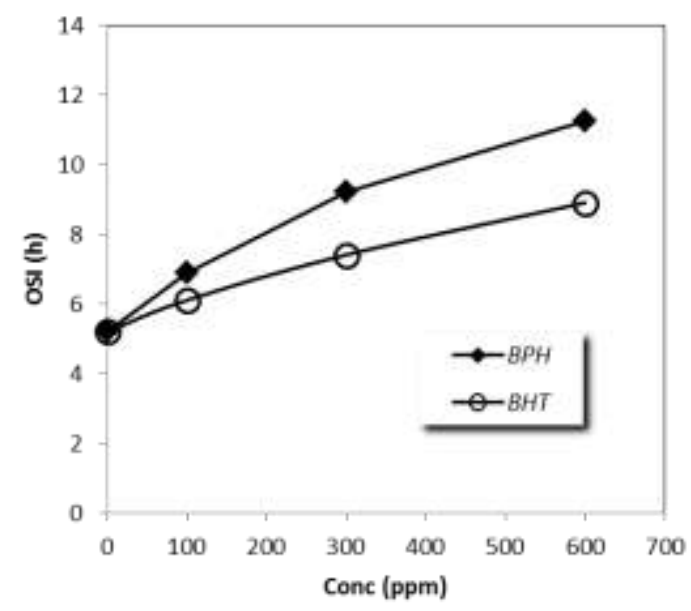

Figure 1 Dependence of the oxidation stability index (OSI) of CME on added $\mathrm{BHT}$ and BPH concentration.

\subsection{Storage and Temperature Effects}

The neat CMEs and those stabilised with antioxidants were stored at 20, 40 and $60^{\circ} \mathrm{C}$ respectively, and the effects of temperature on oxidation stability were examined by the Rancimat test method. The FAMEs were contacted to air 
during storage, but the samples were kept out of the light by being stored in a dark place. The temperature levels were selected by considering the general practice of storing oils, and accelerated oxidation effects were also expected to happen under the selected conditions.

The oxidation stability is of course dependent primarily on the type of biodiesel fuel. It is also affected by other storage parameters, i.e. antioxidant type, antioxidant concentration and storage temperature. The decay of the oxidation stability is naturally suppressed when the antioxidant concentration becomes higher or the storage temperature is lower.

Figures 2shows typical examples of the dependence of oxidation stability on storage time for the CMEs stabilised with BHT (a) or BPH (b), measured at $40^{\circ} \mathrm{C}$ (c). The induction period decreased more at the first stage, e.g. up to eight weeks, and then the decreasing degree became smaller. A similar behavior was observed in the storage tests for 20 and $60^{\circ} \mathrm{C}$.Furthermore, figure 2 shows that the temperature influence was more significant, i.e. the decreasing degree became more prominent at $60^{\circ} \mathrm{C}$. It was evident from the results that the addition of the antioxidants was effective to increase the induction period and therefore the oxidation stability was improved. However, the decreasing behavior indicated clearly that the deterioration degree was faster at the initial stage of storage, and then the rate decreased gradually. Using these phenomena, kinetic analyses were applied to the change of the induction period of oxidation.

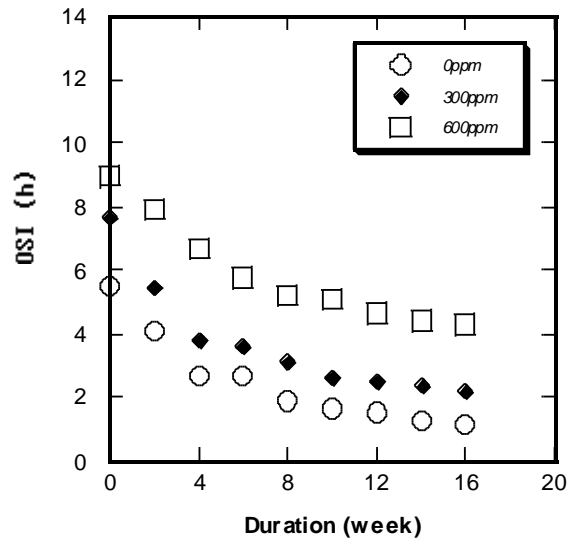

(a)

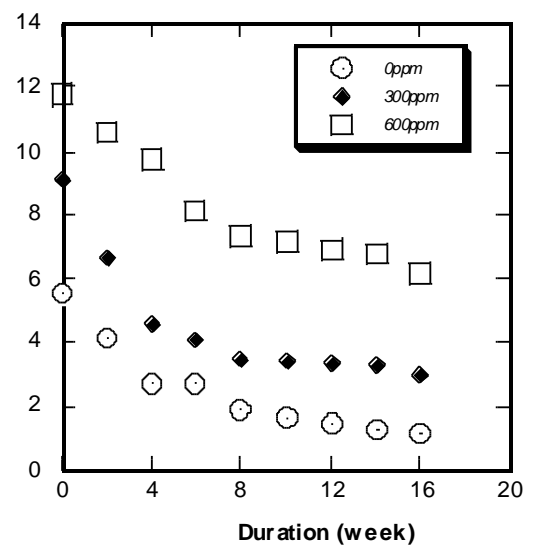

(b)

Figure 2 Influence of antioxidant BHT (a) and BPH (b) addition on the oxidation stability during a 16 -week storage period at $40^{\circ} \mathrm{C}$. 


\subsection{Kinetic Analyses of CME Oxidation}

Taking the decrease of the induction period of oxidation into consideration, kinetic analyses were attempted to examine storage behavior, and its effect on oxidation was investigated from a quantitative viewpoint. The results as shown in Figure 2 were used and kinetic studies were employed to examine the effects of antioxidant addition or temperature during storage.

The logarithmic value of the induction time was obtained and its correlation with the storage time was examined. The result is shown in Figure 3 for the test conducted at $40^{\circ} \mathrm{C}$ and a linear relation between these two parameters is observed. Similar relationships were also observed at 20 and $60^{\circ} \mathrm{C}$. This figure shows that the characteristics of the oxidation stability depended on the CME species, i.e. the slope was steeper for the neat CMEs and the CMEs stabilised with a smaller addition of antioxidants, indicating that the oxidation stability decreased faster.

Taking the decaying linear characteristics into consideration, first-order-like reaction kinetics were employed to elucidate the oxidation stability characteristics of these CME samples, as depicted in Figure 3.

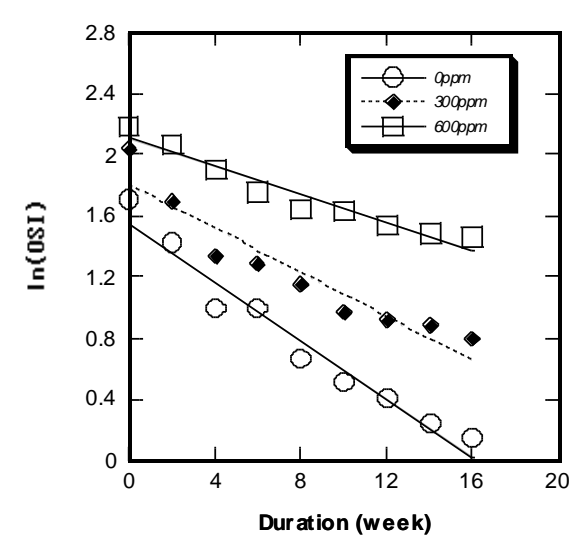

(a)

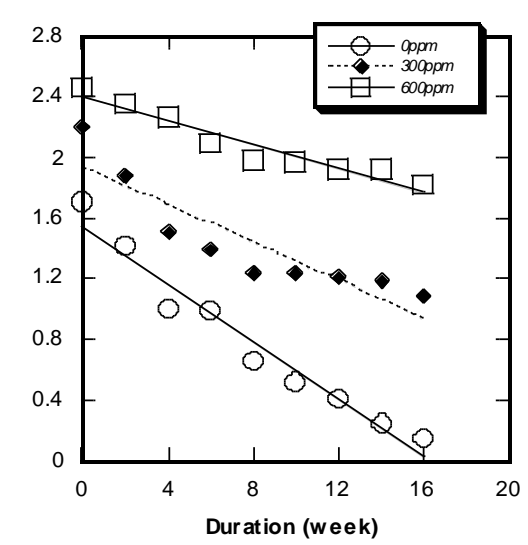

(b)

Figure 3 Correlation between storage time (weeks) at $40^{\circ} \mathrm{C}$ and the logarithmic value of OSI (h) measured by Rancimat test for CME samples with and without addition of antioxidants BHT (a) and BPH (b).

Eq. (1) can be written from a linear relationship observed in the storage test range. In Eq. (1), $k$ is a rate constant and expresses the speed of the oxidation degree, while $t$ represents a storage time. Integrating this equation leads to Eq. (2).

$$
-\frac{d\left(T_{o s}\right)}{\left(T_{o s}\right)}=k d t
$$




$$
\ln \left(T_{o s}\right)=-k t+A
$$

Here, " $A$ " is a constant given by the induction period at the initial stage of storage, and therefore, $A=\ln \left(T_{o s}\right)_{o}$. Eq. (2) is then described in Eq. (3). The rate constant $k$ can be obtained from the induction periods for the initial stage, $\left(T_{o s}\right)_{o}$ and at the storage time of $\mathrm{t},\left(T_{o s}\right)$. Using $\mathrm{k}$, the oxidative degradation levels can be compared to each other.

$$
\ln \left(T_{o s}\right)=-k t+\ln \left(T_{o s}\right)_{0}
$$

The data of $k$ are summarised in Figure 4 for the CME stabilised with BHT (a) and BPH (b), respectively. The oxidation characteristics of the CME appear clearly in this figure, i.e. the value of $k$ becomes higher with an increase of the storage temperature, but is lower if BHT or BPH is added. This indicates that the oxidation of the CME increased with the temperature increase, and was decreased effectively by the addition of the antioxidants. The addition of $600 \mathrm{ppm}$ BHT antioxidant can decrease the oxidation rate up to $47 \%$ at a temperature of 40 and $60^{\circ} \mathrm{C}$, while at a temperature of $20^{\circ} \mathrm{C}$ the decrease of the oxidation rate can reach only $30 \%$ more than 0 ppm of BHT addition. The addition of $600 \mathrm{ppm} \mathrm{BPH}$ antioxidant can decrease the oxidation rate up to $40 \%$ more than the addition of $0 \mathrm{ppm}$ at a temperature of $40 \mathrm{and} 60^{\circ} \mathrm{C}$, while at a temperature of $20^{\circ} \mathrm{C}$ the decrease of the oxidation rate can reach only $12.5 \%$ more than the addition of $0 \mathrm{ppm}$ of BHT. It was shown that BPH performs better than BHT as its suppression of the oxidation rate was 1.23 times that of BHT.

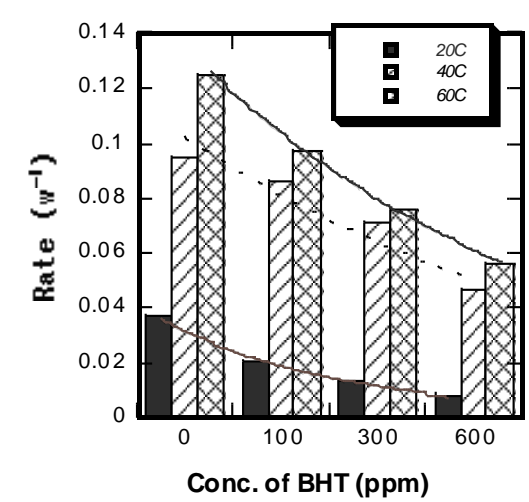

(a)

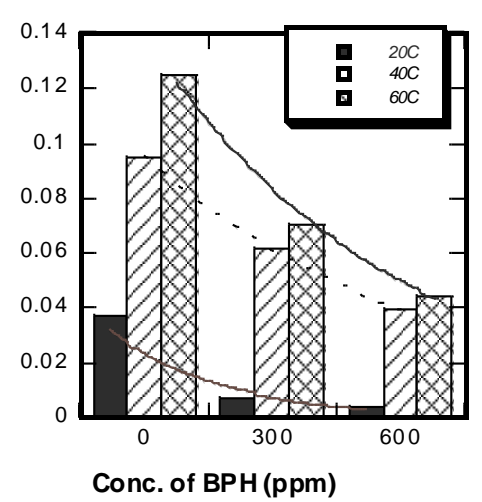

(b)

Figure 4 Dependence of oxidation rate on antioxidant addition, BHT (a) and $\mathrm{BPH}(\mathrm{b})$. 
The activation energy $\left(E_{a}, \mathrm{~J} / \mathrm{mol} \mathrm{K}\right)$ can be obtained by employing $k$ from the Arrhenius equation, which describes the temperature dependence of $k$, as shown in Eq. (4).

$$
\ln k=-\frac{E_{a}}{R T}+B
$$

Here, $R$ is a gas constant $(8.31 \mathrm{~J} / \mathrm{mol} \mathrm{K})$, and $B$ is a constant. $E_{a}$ can be obtained from the relationship of the $\ln k$ value and $\mathrm{T}^{-1}$.The values of $E_{a}$ for the oxidation of the CME stabilised with BHT and BPH are summarised in Figure 5.

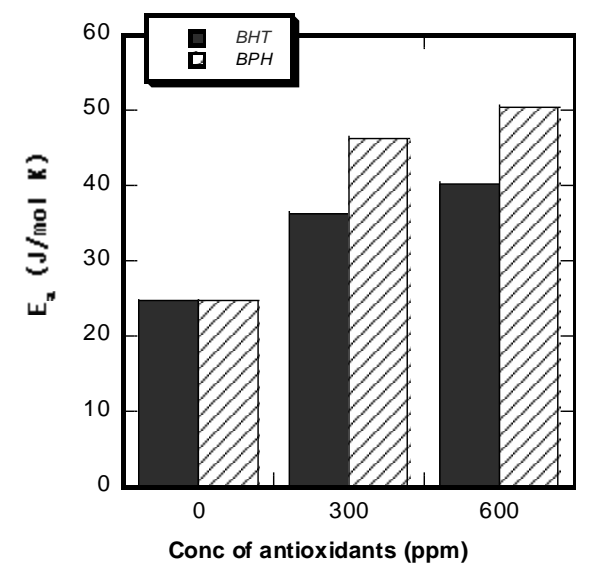

Figure 5 Activation energy $\left(E_{a}\right)$ of neat $\mathrm{CME}$ and of CME added with BHT or $\mathrm{BPH}$ at 300 and $600 \mathrm{ppm}$.

$E_{a}$ indicates the quantity of energy necessary for a chemical reaction, and therefore the effectiveness of an antioxidant can be examined by comparing its activation energies, i.e. reactions with a high barrier need a higher activation energy, while reactions with a low activation energy are low in oxidation resistance. With the addition of antioxidants, $E_{a}$ increased and the oxidation stability of the CME was improved equally. We found that BPH addition at a concentration of $600 \mathrm{ppm}$ increased the size of $E_{a}$ two times more than that of neat $\mathrm{CME}$, and as a result oxidation was suppressed equally. When the effectiveness of BHT and BPH addition were compared, BPH proved to be more effective in increasing the oxidation stability.

\subsection{Generation of Organic Carboxylic Acids during Storage}

The oxidation proceeded during the storage of the CME and generated oxidative products. Among these products carboxylic acids with a low molecular weight appeared, such as formic acid, acetic acid and propionic acid. The CME stored for six months at 20,40 and $60^{\circ} \mathrm{C}$ was extruded in deionised water and the 
quantitative analyses of the carboxylic acids was undertaken by liquid chromatography (Shimazdu, Kyoto, Japan). The results are summarised in Figure 6. The generation of carboxylic acid was not practically observed after six months of storage at a temperature of $20^{\circ} \mathrm{C}$, but along with the increase in storage temperature, the carboxylic acid generation became remarkable and exceeded the standard values by far (10 ppm for acids total). Thus the temperature effects on the oxidation of neat CME were evident. However, the production of these carboxylic acids could be suppressed remarkably by the addition of antioxidants.

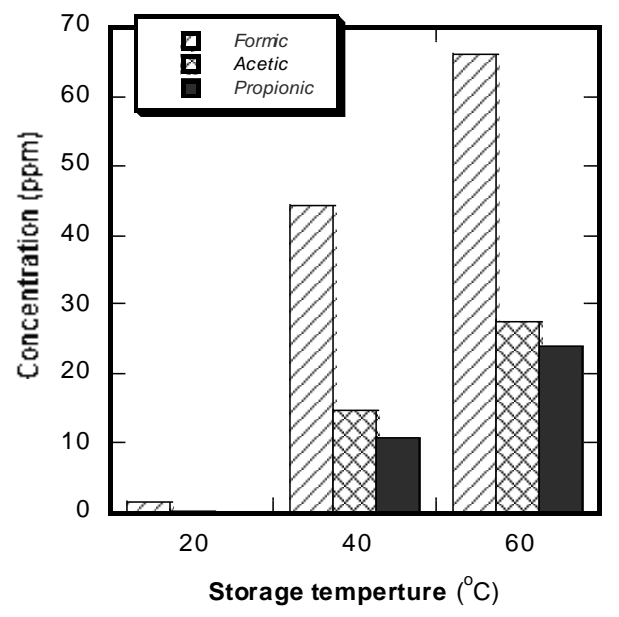

Figure 6 Generation of carboxylic acids in neat CMEs and stored for six months at 20,40 and $60^{\circ} \mathrm{C}$.

\subsection{Oxidation stability vs. Quality Parameter}

Peroxide and carboxylic acid structures are formed on the biodiesel fuel molecules as a result of oxidation, i.e. a chemical reaction of activated oxygen takes place on $\mathrm{C}=\mathrm{C}$ bonds to form a peroxide structure, and oxidation finally leads to carboxylic acids formation. It is interesting to know how the generation of these oxidation products relates to the oxidation stability evaluated by the Rancimat method. For this purpose, the peroxide value (POV) and acid value (AV) were measured during the period that the oxidation stability tests of the Rancimat method were repeated. The correlation between these quality parameters and the oxidation stability characteristics was then investigated. In addition, the kinematic viscosity and water content were measured, and subsequently their correlation with the OSI was examined to clarify the effect of oxidation on these parameters. 


\section{(a) Peroxide value}

Figure $7(a, b)$ shows the changes in the peroxide value for the CME samples stabilised with BHT (a) and BPH (b) and stored at 40 and $60^{\circ} \mathrm{C}$. The peroxide value increased with the increase of the storage time, which was affected by the modification of the CME, i.e. the addition of the antioxidants depressed the formation of peroxide. The POV of the CME added with BPH was relatively small compared to the POV of that added with BHT, and thus BPH was found to be more effective in depressing the peroxide formation.

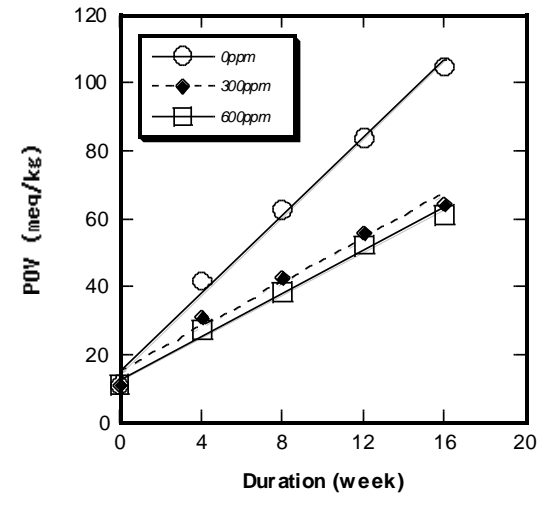

(a)

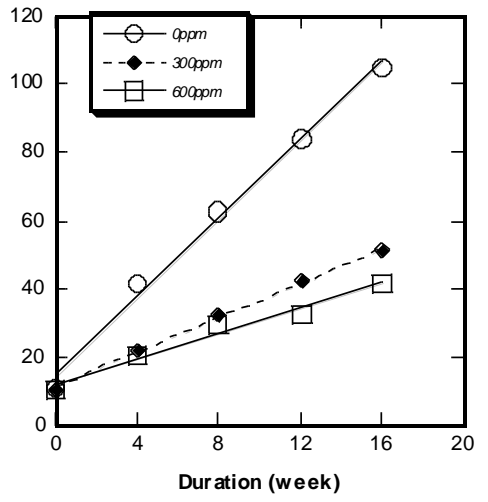

(b)

Figure 7 Peroxide value of CME samples added with BHT (a) and BPH (b) during storage at $40^{\circ} \mathrm{C}$.

The oxidation of the FAME then gave rise to the generation of carbonic acid. The formation of carbonic acid was quantified by a titration method. It should be noted that the generation of carbonic acid may also be caused by hydrolysis of methyl ester bonds during contact with moisture.

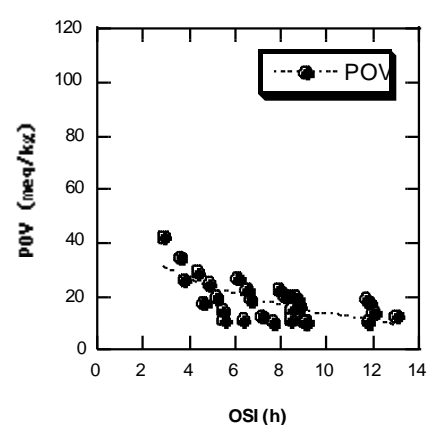

(a)

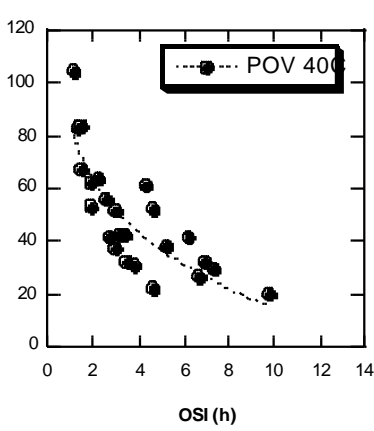

(b)

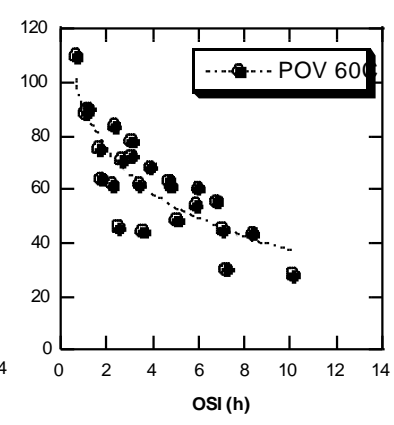

(c)

Figure 8 Correlation between peroxide value (POV) and oxidation stability (OSI) for neat $\mathrm{CME}$ and $\mathrm{CME}$ stabilised with $\mathrm{BHT}$ or BPH during storage at $20^{\circ} \mathrm{C} \mathrm{(a),} 40^{\circ} \mathrm{C}$ (b) and $60^{\circ} \mathrm{C}$ (c). 


\section{(b) Acid value}

The acid value was measured and its changes were observed during storage. Figure 9 shows the correlation between the acid value and the storage time at a temperature of $40^{\circ} \mathrm{C}$ for neat $\mathrm{CME}$ and $\mathrm{CME}$ stabilised with BHT at a concentration of 300ppm and $600 \mathrm{ppm}$ respectively. As depicted in Figure 9, acid values increased gradually with the increase of the storage time and this change was suppressed when the BHTs were added. Similar behavior was observed in the other samples and under different storage conditions. However, the increase was more prominent when samples were stored at higher temperatures.

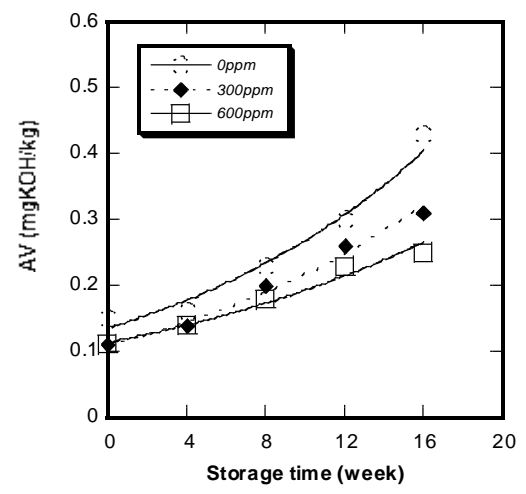

Figure 9 Dependence of acid value on the storage time (at $40^{\circ} \mathrm{C}$ )for neat $\mathrm{CME}$ and CME stabilised with BHT at $300 \mathrm{ppm}$ and $600 \mathrm{ppm}$.

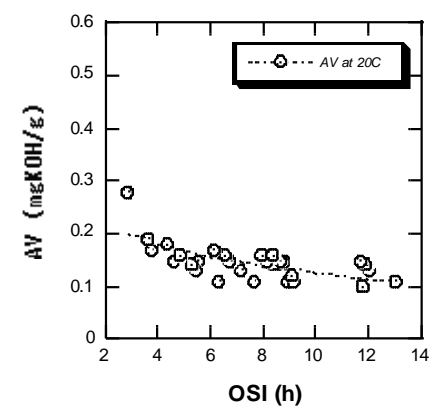

(a)

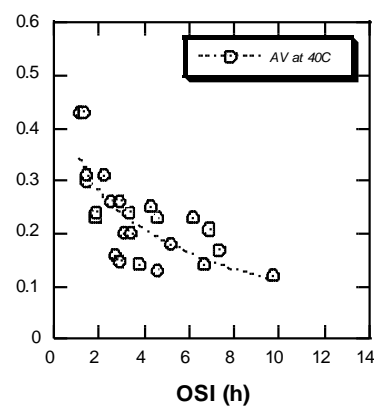

(b)

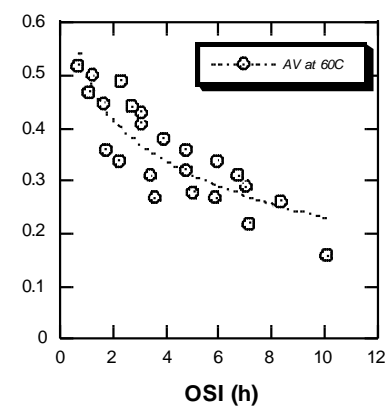

(c)

Figure 10 Correlation between acid value(AV) and oxidation stability index (OSI) for neat $\mathrm{CME}$ and $\mathrm{CME}$ stabilised with $\mathrm{BHT}$ or $\mathrm{BPH}$ during storage at $20^{\circ} \mathrm{C}(\mathrm{a}), 40^{\circ} \mathrm{C}(\mathrm{b})$ and $60^{\circ} \mathrm{C}(\mathrm{c})$.

As described before, the generation of carboxylic acid is mainly caused by the oxidation of FAME molecules. Therefore, the correlation between the acid 
value and the OSI is considered to summarise the results. Figure 10 shows the correlation between the acid value and the OSI for neat CME and CME stabilised with BHT and $\mathrm{BPH}$ stored at $20^{\circ} \mathrm{C}$ (a), $40^{\circ} \mathrm{C}$ (b) and $60^{\circ} \mathrm{C}$ (c), respectively. It is evident that the acid value and the OSI have a significant correlation. As the oxidation degree increases, the OSI is smaller and the acid value is higher. The degree increases with the increase of the storage temperature.

\section{(c) Kinematic viscosity and water content}

The oxidation of ester begins with the build-up of peroxides and carboxylic acid, after which the viscosity starts to increase. During storage, the viscosity of the methyl esters increases by the formation of more polar, oxygen-containing molecules and also by the formation of oxidised polymeric compounds, possibly leading to the formation of gums and sediments that can potentially clog the fuel line. In Figure 11(a), the viscosity data of all samples stored under a storage temperature of 20,40 and $60^{\circ} \mathrm{C}$ are plotted. It is illustrated that theviscosity values slightly increase with the decrease in OSI values, even though they still meet all standard values. Similarly, the water content is higher at lower OSI values, as depicted in Figure 11(b). It can be seen that the water contents lightly increases with the decrease in OSI values. In addition, adsorption of water from the atmosphere during storage cannot be ignored.

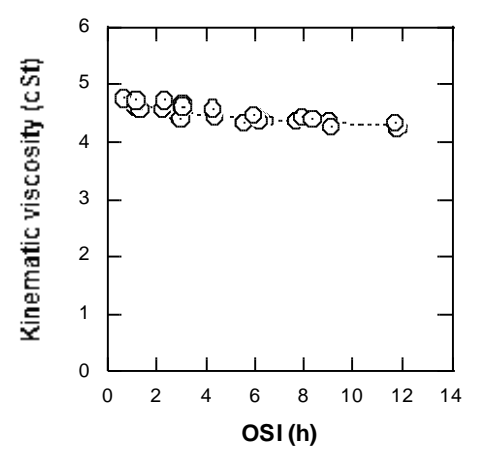

(a)

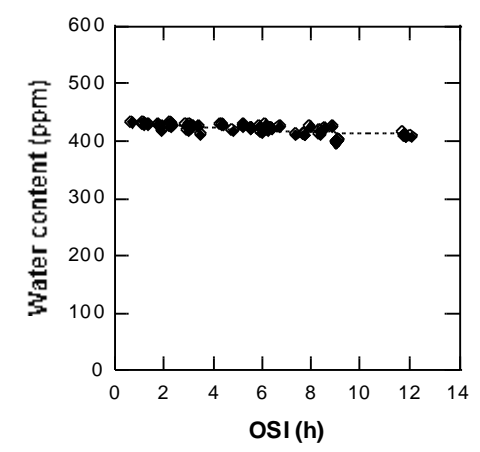

(b)

Figure 11 Correlation between the oxidation stability index (OSI) and the kinematic viscosity (a) and water content (b) for CME stabilised by the mixture of antioxidants BHT and BPH.

\section{Conclusions}

The oxidation stability of neat CMEs and CMEs added with antioxidants during storage were investigated using the Rancimat test method. It is suggested that a 
minimum of $600 \mathrm{ppm}$ of BHT antioxidants or $300 \mathrm{ppm}$ of BPH antioxidants is required to meet the EN14214 biodiesel standards. Effects of antioxidant addition were later compared quantitatively by analysing the value of reaction rate constants obtained from their first-order reaction kinetics. The BPH antioxidant performed better than the BHT antioxidant in this experiment, since the BPH its suppression of the oxidation rate was 1.23 times that of BHT.

In addition, this study observed some changes in other quality parameters during storage, such as an increase in both peroxide value (POV) and acid value (AV). The formation of carboxilic acids such as formic acid, acetic acid and propionic acid caused an increased the AV after the samples were stored for six months under different temperatures.

\section{Acknowledgments}

This research was conducted in Research Center for New Fuels and Vehicle Technology, AIST National Institute of Advanced Industrial Science and Technology, Tsukuba, under the Asia Biomass researcher invitation program funded by NEF (New Energy Foundation), Japan in 2009 and 2010.

\section{References}

[1] Gerpen, J.V., Biodiesel Processing and Production, Fuel Processing Technology, 86, pp. 1097-1107, 2005.

[2] Ramos, M.J., Fernandez, C.M., Casas, A., Rodriguez, L.\& Perez, A., Influence of Fatty Acid Composition of Raw Materials on Biodiesel Properties, Bioresource Technology, 100, pp. 261-268, 2009.

[3] Berchmans, H.J. \& Hirata, S., Biodiesel Production from Crude Jatropha Curcas L. Seed Oil with A High Content of Free Fatty Acids, Bioresource Technology, 99, pp. 1716-172, 2008.

[4] Ma, F. \& Hanna, A.M., Biodiesel Production, Bioresource Technology, 70, pp. 1-15, 1999.

[5] Knothe, G., Gerpen, J.V. \& Krahl, J., Oxidation Stability, The Biodiesel Handbook, 2005.

[6] Knothe, G., Some Aspects of Biodiesel Oxidation Stability, Fuel Processing Technology, 88, pp. 669-677, 2007.

[7] Bouaid, A., Martinez, M. \& Aracil, J., Long Storage Stability of Biodiesel from Vegetable and Used Frying Oils, Fuel,86, pp. 25962602, 2007.

[8] Yamane, K., Kawasaki, K., Sone, K., Hara, T. \& Prakoso, T. Oxidation Stability of Biodiesel and Its Effects on Diesel Combustion and Emission Characteristics, International Journal of Engine Research, 8, pp. 307-319, 2007. 
[9] Mittelbach, M. \& Schober, S., Influence of Antioxidants on The Oxidation Stability of Biodiesel, Journal of American Oil Chemist's Society, 80, pp. 817-823, 2003.

[10] Karavalakis, G., Hilari, D., Givalou, L., Karonis, D. \& Stourna, S., Storage Ability and Ageing Effect of Biodiesel Blends Treated with Different Antioxidant, Energy, 36, pp. 369-374, 2011.

[11] Xin, J., Imahara, H. \& Saka S., Kinetics on The Oxidation of Biodiesel Stabilized with Antioxidant, Fuel, 88, pp. 282-286, 2009.

[12] Asia-Pacific Economic Cooperation, Establishment of the Guidelines for the Development of Biodiesel Standards in the APEC Region, April 2009. 